\title{
Economic evaluation of progeny-testing and genomic selection schemes for small-sized nucleus dairy cattle breeding programs in developing countries
}

\author{
C. M. Kariuki, ${ }^{*}{ }^{1}$ E. W. Brascamp, $\dagger$ H. Komen, $\dagger$ A. K. Kahi, $\ddagger$ and J. A. M. van Arendonk† \\ *Department of Animal Sciences, Chuka University, PO Box 109-60400, Chuka, Kenya \\ †Animal Breeding and Genomics Centre, Wageningen University, PO Box 338, $6700 \mathrm{AH}$ Wageningen, the Netherlands \\ ¥Animal Breeding and Genomics Group, Department of Animal Sciences, Egerton University, PO Box 536-20115, Egerton, Kenya
}

\begin{abstract}
In developing countries minimal and erratic performance and pedigree recording impede implementation of large-sized breeding programs. Small-sized nucleus programs offer an alternative but rely on their economic performance for their viability. We investigated the economic performance of 2 alternative small-sized dairy nucleus programs [i.e., progeny testing (PT) and genomic selection (GS)] over a 20-yr investment period. The nucleus was made up of 453 male and 360 female animals distributed in 8 non-overlapping age classes. Each year 10 active sires and 100 elite dams were selected. Populations of commercial recorded cows (CRC) of sizes 12,592 and 25,184 were used to produce test daughters in $\mathrm{PT}$ or to create a reference population in GS, respectively. Economic performance was defined as gross margins, calculated as discounted revenues minus discounted costs following a single generation of selection. Revenues were calculated as cumulative discounted expressions $(\mathrm{CDE}, \mathrm{kg}) \times 0.32$ $(€ / \mathrm{kg}$ of milk) $\times 100,000$ (size commercial population). Genetic superiorities, deterministically simulated using pseudo-BLUP index and CDE, were determined using gene flow. Costs were for one generation of selection. Results show that GS schemes had higher cumulated genetic gain in the commercial cow population and higher gross margins compared with PT schemes. Gross margins were between 3.2- and 5.2-fold higher for GS, depending on size of the CRC population. The increase in gross margin was mostly due to a decreased generation interval and lower running costs in GS schemes. In PT schemes many bulls are culled before selection. We therefore also compared 2 schemes in which semen was stored instead of keeping live bulls. As expected, semen storage resulted in an increase in gross margins in PT
\end{abstract}

Received August 2, 2016.

Accepted November 18, 2016. ac.ke schemes, but gross margins remained lower than those of GS schemes. We conclude that implementation of small-sized GS breeding schemes can be economically viable for developing countries.

Key words: economic evaluation, small-sized breeding programs, progeny testing, genomic selection

\section{INTRODUCTION}

Dairy production makes an important contribution to poverty reduction and food security in developing countries. Different dairy production systems are present in developing countries, reflecting the wide range in production and marketing conditions (Mburu et al., 2007; Mubiru et al., 2007). Genetic improvement offers an opportunity to improve the efficiency of dairy value chains. Genetic improvement can be realized by importation of exotic germplasm or by local breeding programs. Local breeding programs for developing dairy cattle industries provide a means to address unfavorable genotype by environment interactions resulting from importation of exotic germplasm (Ojango and Pollot, 2002; Vargas and van Arendonk, 2004; Okeno et al., 2010a). However, minimal routine pedigree and performance recording impede the implementation of large-sized breeding programs in many developing countries (Wasike et al., 2011). Small-sized programs may provide the means for improving local genetic resources in countries where infrastructure for large-size pedigree registration and milk recording are lacking (Kariuki et al., 2014). From the literature, it is well known that small-sized breeding programs can create significant genetic gains (Okeno et al., 2010b; Gizaw et al., 2014; Kariuki et al., 2014). However, successful implementation of such programs will ultimately be determined by their economic results.

Recent studies have shown genomic selection (GS) in large-size dairy cattle breeding programs to have genetic and monetary advantages over traditional progeny testing (PT; Schaeffer, 2006; König et al., 2009). Genetic advantages mainly relate to the reduction of 
generation intervals with GS (Goddard and Hayes, 2007). Decrease in generation intervals and elimination of the need for test daughters can result in significant reduction in operational costs for dairy cattle breeding programs (Schaeffer, 2006). Besides reduced costs, GS schemes benefit monetarily from higher annual genetic gains and earlier expression of genetic superiorities. Early expression of genetic superiorities reduces the effect of discounting on revenues (Brascamp, 1978). However, these studies considered large, well-developed breeding programs. Results can therefore not be directly translated to developing countries.

Successful implementation of small-sized nucleus dairy cattle schemes for developing countries faces 2 challenges. First, expected annual genetic gains will be lower because of the smaller size of the breeding population and the smaller number of animals participating in pedigree and performance recording. The second challenge relates to net revenues. Developing dairy cattle sectors are largely dominated by low input-low output smallholder systems. It is therefore challenging for systems to generate the revenues required for an economically sound breeding program. This challenge is particularly important for GS that requires extra investment in the genotyping of selection candidates and the phenotyping and genotyping of the reference population. The first condition for a breeding program is that it generates sufficient revenues to cover operation costs. Economic appraisal of breeding programs is therefore imperative, particularly for high-risk situations in developing countries (Marshall et al., 2011).

A dairy cattle genetic improvement program will result in (a) improved performance at the production level due to the use of superior bulls and (b) increased demand of superior semen. Revenues from genetic improvement are hence realized at 2 separate levels, that is, for the breeding firms selling semen and at the commercial producers where genetic superiority is expressed. Two criteria exist for economic appraisal of breeding programs (Brascamp, 1978). The first criterion focuses on breeding firms and aims at maximization of profits by increasing the semen market share. For such situations, economic appraisal determines the economic effect of changes in market share because of adoption of alternative schemes (e.g., Dekkers and Shook, 1990; Brascamp et al., 1993). The second criterion focuses on producers and aims to increase productivity, reduce production costs, or do both at the commercial producers' level. Such an approach considers a national breeding program in which revenue is generated from sale of end products such as milk or meat (Brascamp et al., 1993; König et al., 2009). For small-sized nucleus schemes in developing countries economic appraisal from a national perspective seems more suitable be- cause the aim of such schemes is to address challenges posed by importation of germplasm (Ojango and Pollot, 2002; Vargas and van Arendonk, 2004; Okeno et al., 2010a). We recently illustrated the feasibility of small-sized GS or PT programs (Kariuki et al., 2014). However, the adoption of such schemes is dependent on their economic performance. The aim of the current study was therefore to economically appraise GS and PT selection strategies for small-sized dairy cattle breeding programs in developing countries from a national perspective.

\section{MATERIALS AND METHODS}

\section{Breeding Program}

Economic evaluation was for a single breeding program under 2 selection strategies, PT and GS. With PT, commercial recorded cows (CRC) were used to provide test daughters; with GS, they were used to create a reference population. In the PT schemes male candidates were evaluated on the performance of their first crop of daughters and parental breeding values, and female candidates were evaluated on their first lactation record and parental breeding values. As a result, under $\mathrm{PT}$, female and male candidates were available for selection from the fourth and sixth year of age onwards, respectively. Selection in the GS strategy in both sexes was solely on genomic breeding values and candidates were available for selection from the first year of age onwards. The effect of the selection strategy on the distribution of selection candidates in the nucleus is shown in Table 1. The breeding objective was to improve milk yield. We used 2 heritabilities (i.e., 0.15 and 0.30 ). Phenotypic standard deviation for milk yield for the Holstein-Friesian population in Kenya was set equal to $1,110 \mathrm{~kg}$ (Ojango and Pollot, 2002; Kahi and Nitter, 2004).

In the face of limited participation of producers in pedigree and performance recording, we evaluated a small-sized nucleus, ignoring inbreeding. The basic structure of the breeding program is illustrated in Figure 1 and is composed of (a) a closed nucleus in which all genetic improvement was generated and (b) a commercial population of 100,000 cows benefiting from genetic improvement in the nucleus. The nucleus was made up of 360 female and 485 male selection candidates (including calves) distributed in eight 1-yrlong age-classes (Table 1). One hundred male and 100 female selection candidates were born annually. Males and females were modeled to attain sexual maturity at the age of $1 \mathrm{yr}$ and were mated immediately after. Consequently, cows dropped their first calf when $2 \mathrm{yr}$ old and had their first performance record by the end of 
The Nucleus

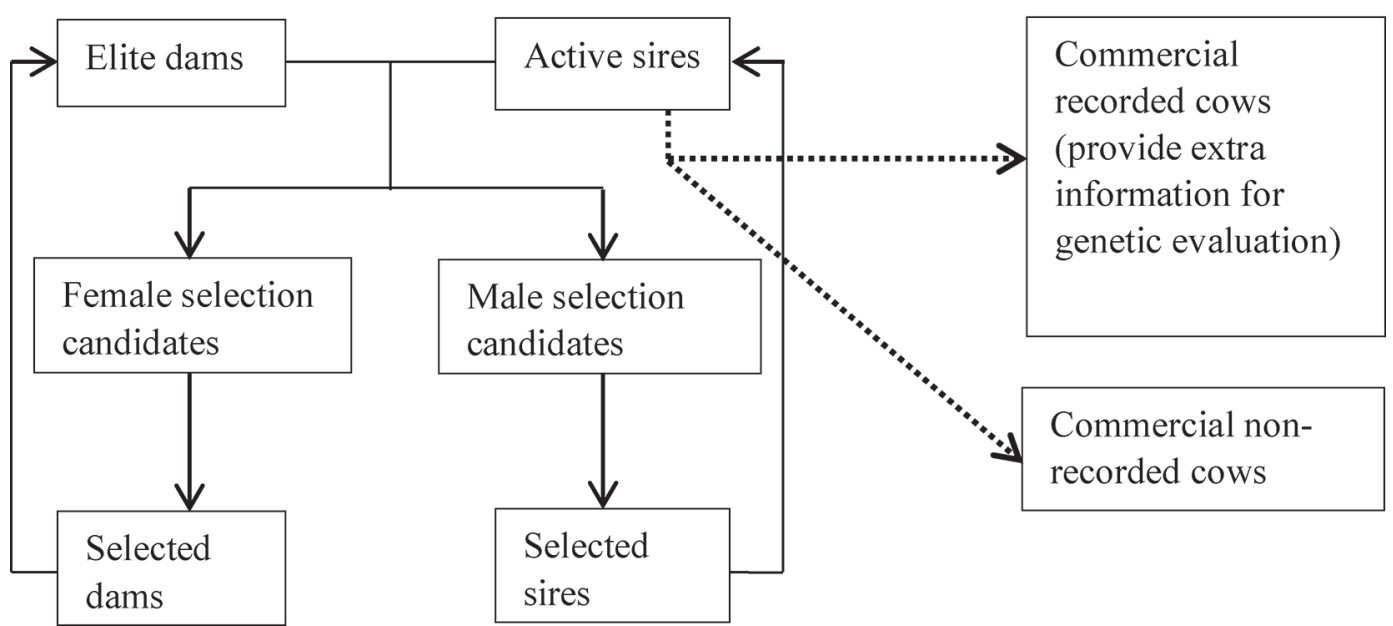

Figure 1. The general breeding structure considered.

their third year. Each year 100 elite dams and 10 active sires were selected. Survival rate was fixed at 0.85 and 0.75 for males and females, respectively.

Size of CRC Population. Two sizes of CRC population were considered, where CRC are performancerecorded commercial cows. In determining the required number of CRC, we worked from the hypothesis that PT was the most feasible selection strategy for developing countries (Marshall et al., 2011). Because of the low participation of producers in recording, we considered relatively small numbers of test daughters per candidate bull. We modeled 2 situations in which (a) each candidate bull had 15 complete daughter records
(DR) and (b) each candidate had 30 DR. Therefore, the size of the CRC population for each situation was determined by the conception rate in CRC, sex ratio at birth, and survival of test daughters, fixed at $0.80,0.50$, and 0.75 , respectively. Candidate bulls were mated to CRC at the start of their second year (because of culling only 85 of the candidate bulls were evaluated; Table 1). In addition, daughter records were available at the start of their fourth year of life; that is, records were only available from daughters surviving to $3 \mathrm{yr}$ of age. Therefore, to obtain 15 and $30 \mathrm{DR}$ per candidate bull, we required a total of 12,593 and 25,184 CRC, respectively. We denoted the PT scheme with 15 DR per

Table 1. Information on the structure of the nucleus and the effects of involuntary culling on the number of selection candidates across ageclasses for progeny-testing (PT) and genomic selection (GS) criteria

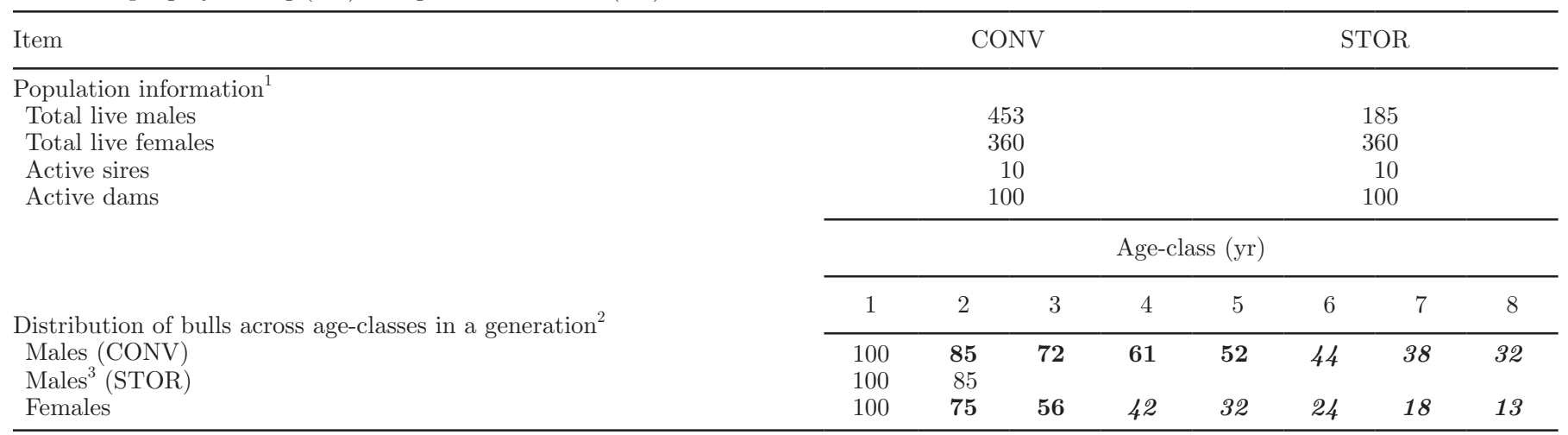

\footnotetext{
${ }^{1} \mathrm{CONV}=$ no semen storage; $\mathrm{STOR}=$ semen storage.
}

${ }^{2}$ Refers to the total number of males and females maintained as live animals in a generation; they include selection candidates and active sires and dams; bold numbers indicate the ages at which selection candidates were available for selection; italic numbers relate to PT schemes.

${ }^{3}$ With STOR, the number of male selection candidates from age-class 3 to 8 was equal to 85 ; that is, we modeled a situation in which sufficient amounts of semen were stored to allow evaluation of all 2-yr-old bulls in subsequent age-classes after voluntary culling. However, bull selection criteria were the same as with CONV. 
candidate bull as PT15 and that with 30 DR as PT30. Under GS schemes, the same sizes of CRC populations were considered, but they were used to create a reference population. Equivalent GS schemes were denoted as GS15 and GS30.

Use of Bulls. Bull maintenance costs can be reduced by early culling combined with semen storage. In addition, early storage of semen overcomes the decline in the number of selection candidates over time resulting from involuntary culling when using fresh semen (Skjervold and Langholz, 1964). We therefore compared the economic significance of a situation in which semen was frozen and stored and bulls culled (STOR) against the conventional system in which only fresh semen is used and bulls are maintained as live animals in the bull-station (CONV) for both GS and PT strategies. For STOR, we assumed that the entire amount of semen required for production of test daughters and insemination of commercial cows was collected and stored from 2-yr-old bulls, after which they were culled, irrespective of the selection strategy. The amount of semen collected was determined by number of cows to be inseminated and number of straws required per conception (fixed at 1.7). For CONV semen for production of test-daughters was collected from 2-yr-old bulls, while semen for use on the commercial herd was collected from selected sires in both PT and GS schemes.

Deterministic Simulations of Genetic Superiorities. Genetic superiorities were determined through deterministic simulation based on pseudo-BLUP selection index theory with 8 non-overlapping age-classes (Hazel, 1943; Ducrocq and Quaas, 1988; Villanueva et al., 1993):

$$
\Delta G=\frac{\sum_{j=1}^{\text {no. of age-classes }} i_{j} r_{I H, j} \sigma_{A, j} \frac{n_{j}}{n_{\text {total }}}}{L},
$$

where $\Delta G$ is annual genetic gain, $i_{j}, r_{I H, j}, \sigma_{A, j}$, and $\frac{n_{j}}{n_{\text {total }}}$ were intensity of selection, accuracy, additive genetic standard deviation, and the proportion of parents in the $j$ th age-class, and $L$ the generation interval. All simulations were implemented in SelAction (Rutten et al., 2002). The program accounts for reduction in variance due to selection (Bulmer, 1971). In addition, it also corrects selection intensities for finite population sizes (Meuwissen, 1991).

Genetic superiorities for GS breeding programs were simulated by including an "extra" correlated trait with heritability equal to unity in the model as suggested by Dekkers (2007). Genetic and phenotypic correlations between the true and "extra" trait were calculated as $r_{g \hat{g}}$ and $h r_{g \hat{g}}$, respectively, where $h$ is the square root of the heritability and $r_{g \hat{g}}$ the accuracy of genomic EBV which was calculated based on Dekkers (2007):

$$
r_{g \hat{g}}=\sqrt{\frac{\lambda \mathrm{h}^{2}}{\lambda \mathrm{h}^{2}+1}}
$$

where $\lambda=n_{P} / n_{G} ; n_{G}$ depends on the size of historic effective base population size $\left(N_{E}\right)$ and the size of the genome $(L)$ in Morgan and was computed as $n_{G}=2 N_{E} L$. $N_{E}$ was equal to 156 (Muasya et al., 2013) and $L$ was equal to $30 ; n_{P}$ was the size of the reference population (i.e., 12,593 and 25,184), and $\mathrm{h}^{2}$ was heritability.

\section{Economic Evaluation}

Comparison of the economic performance of the selection strategies was based on gross margins, which we defined as the difference between discounted revenues and discounted costs. Revenues were defined as expressed genetic gains in the commercial cow population following one generation of selection. Revenues were computed as cumulative discounted expressions (CDE; Brascamp, 1978), expressed in kilograms and for a time horizon of $20 \mathrm{yr}$. Revenues and costs were discounted to the year of birth of selection candidates.

Gene flow method was used to model the passage of genetic superiorities from selected parents to offspring in subsequent age by sex classes through reproduction and aging. An age-class was a 1-yr period. Gene frequencies per sex in an age-class at a particular year $t$ was expressed by a vector $\mathbf{m}_{t}$, which was calculated as (Brascamp, 1978)

$$
\mathbf{m}_{t}=\mathbf{R n}_{t-1}+\mathbf{P m}_{t-1}
$$

where $\mathbf{R}$ is a matrix defining gene transmission through reproduction, $\mathbf{P}$ is a matrix defining gene transmission through reproduction and aging, and

$$
\mathbf{n}_{t}=\mathbf{Q} \mathbf{n}_{t-1},
$$

where $\mathbf{n}$ is a vector with gene frequencies in the first age class, and $\mathbf{Q}$ is a matrix defining aging. Cumulative discounted expressions (CDE) were calculated as (Brascamp, 1978):

$$
\mathrm{CDE}=\sum_{t=1}^{20} \mathbf{m}^{\prime}(t) \mathbf{h}\left(\frac{1}{1-r}\right)^{t},
$$

where $\mathbf{m}$ is a vector with gene frequencies in defined age-classes in all tiers by sex subclasses originating from 
the selected parents, $\mathbf{h}$ is an incidence vector describing the relative frequency of expression of the trait, and $r$ is the discount rate, which was fixed at 4 and $7 \%$. Vector $\mathbf{h}$ was determined based on expected proportions of lactating cows in different age-classes and effects of age on milk production. All calculations were done using the program GFLOW (Brascamp, 1978). Revenues were calculated as

$$
\text { Revenue }=\mathrm{CDE} \times 0.32 \times 100,000,
$$

where 0.32 is the value in euros of $1 \mathrm{~kg}$ of raw milk in Kenya and 100,000 represents the size of the commercial population.

Gene Flow Pathways. Proportions of selected sires and dams from different age-classes were determined through truncation on estimated breeding values (Ducrocq and Quaas, 1988). Gene flow pathways were categorized as (a) flow of genes within the nucleus and (b) flow of genes from the nucleus to the commercial population. Within the nucleus, we accounted for flow of genes from sires and dams to male and female offspring. Flow of genetic superiority from the nucleus to commercial cows was through use of selected ("elite") nucleus sires to breed commercial cows. For simplicity, the effect of use of young sires on the CRC was ignored. No selection occurred in the commercial herd.

The $\mathbf{R}$ and $\mathbf{P}$ matrices for the alternative strategies were determined by the age at which selection was done. With PT schemes sires were evaluated and selected based on daughter performances. Dams in the nucleus were evaluated and available as selection candidate after they completed their first lactation. As a result, for the PT strategy sires were available for selection from 6 yr of age and dams from 4 yr. For the GS strategy, sires and dams were selected based on genomic information early in life and were available for selection from the first year of age.

\section{Calculation of Costs}

Data on costs were collected through a group discussion with stakeholders in Kenya. The stakeholders included dairy farmers and representatives from government agencies involved in livestock genetic improvement, such as the Livestock Recording Centre (involved with performance recording and genetic evaluations), Kenya Animal Genetic Resources Centre (maintains the bull station), Kenya Agricultural Research Institute, and the Ministry of Agriculture.

We assumed that the nucleus was composed of individually owned commercial farms with consistent recording history where female candidates and elite dams were housed, and a government-owned bull station where male candidates and active sires were maintained. Only costs for running the bull station for a single generation (i.e., 8 yr) were considered. Total costs were discounted to the first year. Maintenance costs for female candidates and selected dams was borne by the producers and were assumed to be equal for both schemes (except for genotyping costs).

Labor, Health, Feed, and Housing Costs. Labor costs were defined as costs for hire of personnel involved in the daily management of bulls in the station. The average labor requirement under the Kenya situation was estimated to be 1 person for every 10 bulls. Distinction was not made for the age of bulls. The average monthly labor cost per individual laborer was €136.

Health costs were due to routine parasite and disease control. Costs were for purchase of dip compounds and oral anthelmintics. Deworming and dipping were done 4 times per year. Dipping costs and deworming costs were fixed at €9.5 and €3.5 per animal, respectively.

The main feed sources were hay, concentrates, and mineral licks. The costs for a $15-\mathrm{kg}$ hay bale, $70-\mathrm{kg}$ sack of concentrates, and $2-\mathrm{kg}$ sack of mineral salts were $€ 2.3$, €22.7, and €3.6, respectively. Feeding costs per bull per year were fixed at $€ 509$.

In the present study we included a fixed value of $€ 3$ per month per animal as the housing costs.

\section{Bull-Dam Contracting and Insemination} Costs. Bull-dam contracting and insemination costs included contracting elite dams and insemination. Insemination of CRC with young bulls was accounted as a bull station cost. Cost were $€ 455$ for contracting a bull-dam and $€ 45$ per insemination.

Genotyping Costs. Genotyping costs comprised costs for sample collection, DNA extraction, and genotyping. Total genotyping cost per animal was set at $€ 50$. Genotyped animals were bulls and cows in the nucleus and cows in the reference population. Genotyping of bulls and cows was done annually for each new batch of calves born in the nucleus. For the reference population, we assumed the CRC to reflect the initiation of genomic selection. The CRC were therefore modeled to have been genotyped at the same time. However, future generations will benefit from genomic information obtained from this initial group. To account for future gains attributable to genomic information from the initial group, we modeled a situation in which funds for genotyping were borrowed from a commercial entity and repaid within 10 yr. The principal amount borrowed was equal to the actual genotyping costs. An interest rate of $11 \%$, based on the average interest rate for Kenya Central Bank (CBK, 2016) for the period between January and June 2016, was charged. Total amount repayable after $10 \mathrm{yr}$ was calculated as $T=$ 
$P(1+r t)$, where $T$ is the total repayable amount, $P$ is the borrowed amount, $r$ is the interest rate charged, and $t$ is equal to $10 \mathrm{yr}$. For simplicity, we assumed a fixed-rate interest paid annually. Amount repaid annually was calculated as $T / 10$. The CRC genotyping cost was fixed as the repayment amount for the initial year.

Semen Collection Costs. The cost of semen collection was fixed at $€ 2.5$ per straw. Costs for storage of semen and purchase of storage containers and liquid nitrogen were ignored.

\section{RESULTS}

\section{Genetic Superiorities for Alternative CONV PT and GS Schemes}

Table 2 presents genetic superiorities per generation, accuracy of selection for sires at the latest age of selection $\left(\mathbf{r}_{\mathrm{IH}}\right)$, and average generation intervals $(\overline{\mathrm{L}})$ for alternative PT and GS schemes. Overall, $\mathrm{r}_{\mathrm{IH}}$ was higher for equivalent PT schemes. As expected, $\mathrm{r}_{\mathrm{IH}}$ were higher with higher $\mathrm{h}^{2}$ and larger size of CRC population (number of offspring). In addition, PT schemes also had higher genetic superiorities than equivalent GS schemes. For instance, genetic superiorities in the sire pathway were less by 24 and $18 \%$ for GS15 scheme compared with the PT15 scheme for $\mathrm{h}^{2}$ equal to 0.15 and 0.30 , respectively. Further, the sire pathway in the GS30 scheme had 19 and 12\% lower genetic superiorities than the same pathway in the PT30 scheme for $\mathrm{h}^{2}$ equal to 0.15 and 0.30 , respectively. In comparison, for PT schemes $\overline{\mathrm{L}}$ were on average 2.36 times longer than for GS schemes. Annual genetic gain $(\Delta \mathbf{G})$ was 35 and $61 \mathrm{~kg}$ for PT15 scheme and 73 and $135 \mathrm{~kg}$ for GS15 scheme for $\mathrm{h}^{2}$ equal to 0.15 and 0.30 , respectively, and
$\Delta \mathrm{G}$ was 41 and $77 \mathrm{~kg}$ for PT30 scheme and 95 and 168 $\mathrm{kg}$ for GS30 scheme for $\mathrm{h}^{2}$ of 0.15 and 0.30 , respectively.

\section{Effect of Semen Storage on Genetic Superiorities}

Semen storage (STOR) had a greater effect on genetic superiorities in PT schemes compared with GS schemes (Table 2). For PT15 schemes STOR increased genetic superiorities by $15 \%$ irrespective of the heritability, while for GS15 schemes the increase was $2 \%$. Higher genetic superiorities in STOR resulted from an increase in number of selection candidates across ageclasses (Table 1). For CONV the number of selection candidates in later age-classes was lower because of culling. However, the number of selection candidates with STOR was constant across age-classes and was determined by the number of bulls in age-class 2 . Consequently, STOR schemes had higher intensities across male-age classes than CONV.

\section{Cumulative Genetic Gains for Alternative PT and GS Schemes}

Table 3 presents the cumulative genetic gain in the commercial cow population for alternative PT and GS schemes in the 20th year. The cumulative genetic gain was derived as the CDE over the investment period at $0 \%$ discounting. It reflects the genetic level that results from running the same program over time. Overall, GS had higher cumulative genetic gains compared with PT for both CONV and STOR schemes. For CONV schemes with $\mathrm{h}^{2}$ equal to 0.15 , GS15 and GS30 schemes had 115 and $134 \%$ higher cumulative genetic gains than PT15 and PT30 schemes, respectively. Similarly, for $\mathrm{h}^{2}$ equal to 0.30 , cumulative genetic gains were 129 and

Table 2. Genetic superiorities per generation (annual genetic gain, $\Delta \mathrm{G}$ ) for milk yield (kg), accuracy of selection for sires only ( $\mathrm{r}_{\mathrm{IH}}$ ), and average generation intervals $(\overline{\mathrm{L}})^{1}$

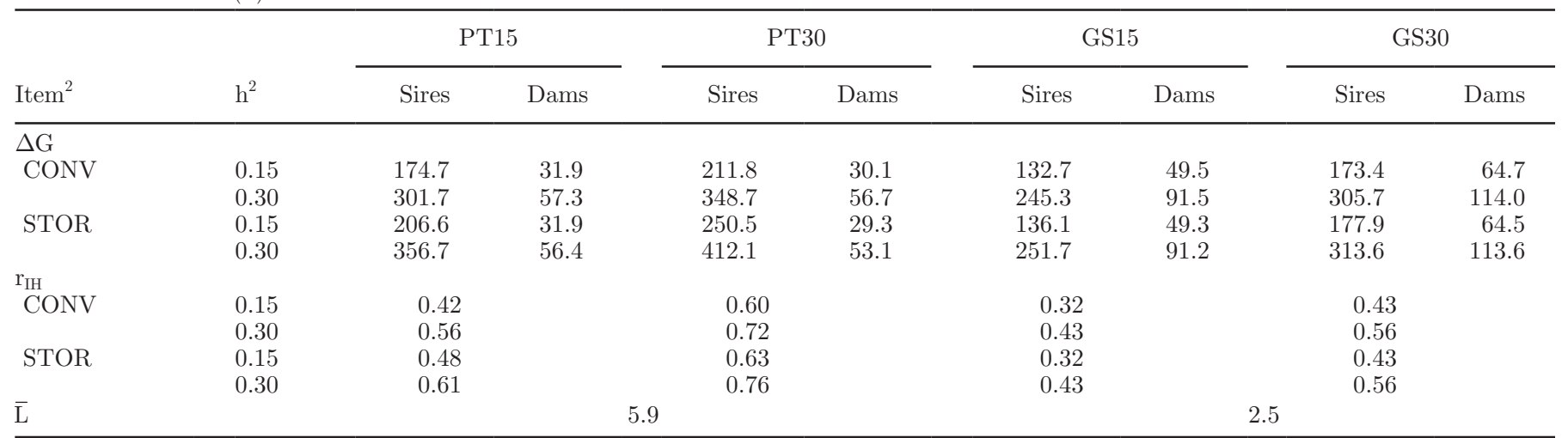

${ }^{1}$ PT15 and PT30 are progeny-testing schemes with 12,592 and 25,184 cows in the commercial population, respectively; GS15 and GS30 are equivalent genomic selection schemes with commercial cows used as the reference population.

${ }^{2} \mathrm{CONV}=$ no semen storage; STOR $=$ semen storage. 
Table 3. Cumulative genetic superiority (cumulative discounted expressions with $0 \%$ discounting) for milk yield $(\mathrm{kg})$ in the commercial cow population after $20 \mathrm{yr}^{1}$

\begin{tabular}{lccccc}
\hline & \multicolumn{2}{c}{ CONV } & & \multicolumn{2}{c}{ STOR } \\
\cline { 2 - 3 } \cline { 5 - 6 } Scheme $^{2}$ & $\mathrm{~h}^{2}=0.15$ & $\mathrm{~h}^{2}=0.30$ & & $\mathrm{~h}^{2}=0.15$ & $\mathrm{~h}^{2}=0.30$ \\
\hline PT15 & 193.0 & 333.9 & & 226.1 & 391.1 \\
PT30 & 231.2 & 381.8 & & 271.3 & 447.9 \\
GS15 & 414.3 & 765.9 & & 422.8 & 781.6 \\
GS30 & 541.6 & 954.6 & & 552.7 & 974.2 \\
\hline
\end{tabular}

${ }^{1} \mathrm{CONV}=$ no semen storage; STOR $=$ semen storage.

${ }^{2} \mathrm{PT} 15$ and PT30 are progeny-testing schemes with 12,592 and 25,184 cows in the commercial populations, respectively; GS15 and GS30 are equivalent genomic selection schemes with cows used as the reference populations.

$150 \%$ higher for GS15 and GS30 in contrast to equivalent PT15 and PT30 schemes, respectively. In addition, differences in cumulative genetic gains were influenced by selection pathways; selection in sires had a larger effect than selection in dams.

Moreover, STOR resulted in increased cumulative genetic gains for both PT and GS schemes. However, the increase was larger for PT schemes than for GS schemes. With $\mathrm{h}^{2}$ equal to 0.15 , increase in cumulated genetic gains for PT15 and PT30 schemes was 33.1 and $40.1 \mathrm{~kg}$, while for GS15 and GS30, it was 8.5 and 11.1 $\mathrm{kg}$, respectively.

\section{Costs for Alternative CONV and STOR PT and GS Schemes}

Table 4 presents a breakdown of costs for CONV and STOR schemes at $4 \%$ discounting and $\mathrm{h}^{2}$ equal to 0.30 . Costs related to production of test daughters (i.e., semen collection and insemination of CRC) were higher than the cost for genotyping. Consequently, CONV
PT schemes had higher overall costs than equivalent CONV GS schemes. In comparison, STOR resulted in lower bull maintenance costs but higher semen collection costs. However, the decrease in bull maintenance costs was larger than the increase in semen collection costs, resulting in a decrease in the overall costs for STOR compared with CONV schemes. As expected, schemes with larger CRC population size had higher costs. Similar observations were made for $\mathrm{h}^{2}=0.15$ and for a $7 \%$ discount rate (results not shown).

\section{Gross Margins for Alternative CONV GS and PT Schemes}

Figure 2 presents gross margins for alternative CONV PT and GS schemes at 4 and $7 \%$ discounting and $\mathrm{h}^{2}$ equal to 0.15 . Generally, gross margins were positive for all schemes, and GS schemes had higher gross margins than equivalent PT schemes. With $\mathrm{h}^{2}$ equal to 0.15 and $4 \%$ discount rate, using GS instead of PT for a situation with 12,592 CRC (GS15), increased gross margins 4.2

Table 4. Discounted costs (thousands of Euros at $4 \%$ discount rate and $\mathrm{h}^{2}=0.30$ ) for CONV and STOR progeny-testing (PT) and genomic selection schemes ${ }^{1}$

\begin{tabular}{|c|c|c|c|c|c|c|}
\hline \multirow[b]{2}{*}{ Bull use } & \multirow[b]{2}{*}{ Scheme } & \multicolumn{5}{|c|}{ Cost $\left(\times 10^{3} €\right)$} \\
\hline & & $\begin{array}{c}\text { Bull } \\
\text { maintenance }^{2}\end{array}$ & $\begin{array}{l}\text { Contracting and } \\
\text { insemination }^{3}\end{array}$ & $\begin{array}{l}\text { Semen } \\
\text { collection }\end{array}$ & Genotyping & Total \\
\hline \multirow{3}{*}{ CONV } & PT30 & 376 & 1,042 & 1,111 & 0 & 2,521 \\
\hline & GS15 & 376 & 61 & 1,008 & 152 & 1,528 \\
\hline & GS30 & 376 & 61 & 1,008 & 222 & 1,666 \\
\hline \multirow{3}{*}{ STOR } & PT30 & 110 & 1,042 & 1,329 & 0 & 2,481 \\
\hline & GS15 & 110 & 61 & 1,226 & 152 & 1,549 \\
\hline & GS30 & 110 & 61 & 1,226 & 222 & 1,619 \\
\hline
\end{tabular}

${ }^{1} \mathrm{CONV}=$ no semen storage; STOR $=$ semen storage; PT15 and PT30 are progeny-testing schemes with 12,592 and 25,184 cows in the commercial populations; GS15 and GS30 are equivalent genomic selection schemes with commercial cow populations being used as the reference populations.

${ }^{2}$ Bull maintenance costs include costs for feeding, housing, health, and labor.

${ }^{3}$ Contracting and insemination costs include costs for contracting bull dams and insemination of bull dams and commercial recorded cows. 


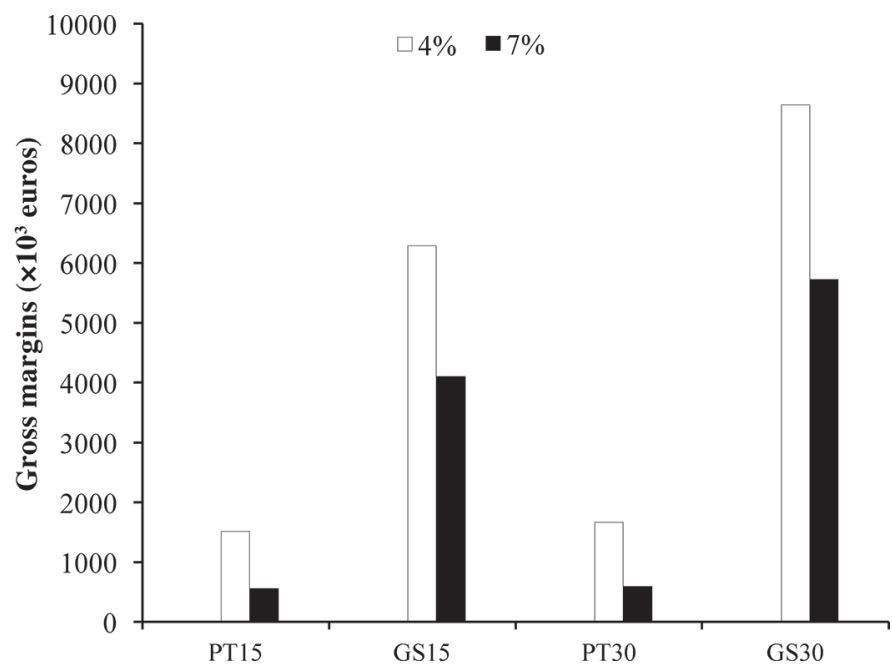

Figure 2. Gross margins for alternative conventional (no semen storage) progeny-testing (PT) and genomic selection (GS) schemes with $\mathrm{h}^{2}=0.15$ and discount rates equal to 4 and $7 \%$ for $20 \mathrm{yr}$ following one generation of selection. PT15 and PT30 are progeny-testing schemes with 12,592 and 25,184 commercial recorded cows; GS15 and GS30 are equivalent genomic selection schemes with commercial recorded cows used as the reference population.

fold, while for a situation with 25,184 CRC (GS30) the increase was 5.2 fold. For $h^{2}$ equal to 0.30 , these ratios were 3.2 (GS15) and 3.7 (GS30). Increase in $\mathrm{h}^{2}$ resulted in an increase in gross margins for all schemes. With $\mathrm{h}^{2}$ equal to 0.30 and $4 \%$ discount rate, gross margins were (in thousands of Euros) 4,070, 12,984, 4,406, and 16,505 for PT15, GS15, PT30, and GS30, respectively.

\section{Economic Effect of Semen Storage}

Figure 3 presents the increase in gross margins resulting from semen storage for PT and GS schemes. Progeny-testing schemes benefitted the most from STOR, with between 26 and $54 \%$ increases in gross margins compared with between 0.3 and $3.4 \%$ increases in GS schemes. However, despite these increases GS schemes had higher overall gross margins.

\section{DISCUSSION}

\section{Genetic Performance}

Small-sized nucleus dairy cattle breeding scheme in developing countries can increase efficiency of production for smallholder producers (Hinks, 1974; Rege et al., 2011). Strategies to maximize the utility of such programs would be advantageous for the entire value chain (Nicholas and Smith, 1983). In the present study we investigated the economic feasibility of such programs and opportunities to maximize their utility in terms of genetic gains and profitability. Genetic and economic performance for PT and GS under a developing dairy industry situation were investigated. Genetic performance of the alternative strategies was based on CDE (Brascamp, 1978). Our results show that smallsized nucleus breeding programs can create significant genetic gains in the commercial cow population. In addition, GS resulted in higher genetic gains in the commercial population than PT. For instance, the genetic gain in the commercial population was $150 \%$ higher for the GS30 scheme compared with the PT30 scheme.

Differences in the genetic performance between GS and PT relate to their effects on accuracy and generation intervals (Goddard and Hayes, 2002; Kariuki et al., 2014). Progeny testing schemes had much higher accuracies compared with GS schemes. This finding is in agreement with the literature that indicates that GS schemes require a very large number of cows in the reference population to achieve high accuracies (Meuwissen et al., 2001; Goddard and Hayes, 2007). However, for small-sized programs it is difficult to increase the reference population (at least in the short term) because of minimal recording among producers. However, GS reduced the generation intervals by more than $50 \%$, which resulted in the genetic gain of the commercial cow population being more than $87 \%$ higher.

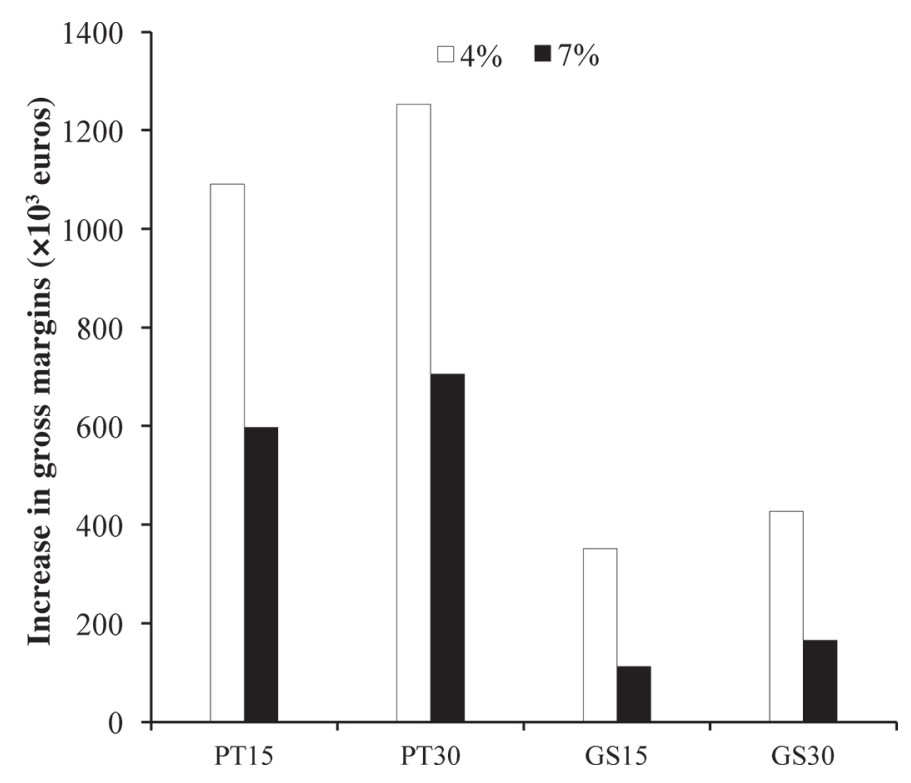

Figure 3. Increase in gross margins due to adoption of semen storage for progeny-testing (PT) and genomic selection (GS) schemes with $\mathrm{h}^{2}=0.30$ and discount rates of 4 and $7 \%$. PT15 (30) = progeny-testing schemes with 12,592 $(25,184)$ commercial recorded cows; GS15 $(30)=$ equivalent genomic selection schemes with commercial recorded cows used as the reference populations. With $\mathrm{h}^{2}=0.30$ and $4 \%$ discount rate, gross margins were (in thousands of Euros) 4,070, 12,984, 4,406, and 16,505 for PT15, GS15, PT30, and GS30, respectively. 
This study confirms earlier findings that despite lower accuracy, even small-sized GS schemes can outperform PT schemes in annual genetic gains (Schaeffer, 2006; König et al., 2009).

\section{Costs}

Costs are an important factor in deciding on any business investment. The common notion is that GS schemes are more costly to run because they require genotyping of many individuals (Marshall et al., 2011). In contrast, our results show that PT breeding programs are more expensive to run. Costs involved in production of test daughters for evaluation of young bulls were higher than genotyping costs. This outcome is in agreement with the literature (Schaeffer, 2006; König et al., 2009). In our study, we fixed the genotyping cost to $€ 50$ per individual, which reflects the current costs for DNA collection and genotyping with a $64 \mathrm{k}$ SNP (Erwin Koenen, CRV, Arnhem, the Netherlands; personal communication). In addition, advances in genotyping technologies will lead to further declines in genotyping costs (Guichoux et al., 2011; Shendure and Aiden, 2012). We charged the full costs of milk recording to the breeding program where some of these costs might be charged to the farmer because it also provides information for herd management. The reductions in costs of phenotyping are expected to be smaller. Genetic selection rather than PT is therefore more likely to become cheaper in the future.

\section{Semen Storage}

Semen freezing coupled with voluntary culling of bulls early in life can be an effective cost cutting measure for both GS and PT schemes (Skjervold and Langholz, 1964). This measure reduced bull maintenance costs by $71 \%$ for both strategies. In addition, STOR schemes had slightly higher CDE because of an increase in the numbers of selection candidates and thereby higher selection intensities because of the elimination of the effect of culling. As expected, the increase in CDE was more for PT schemes in which selection occurs late in life. Small breeding programs can therefore use semen freezing to improve their economic performance, especially for PT schemes.

\section{Economic Performance}

The primary purpose for the present study was to determine whether small-sized nucleus dairy breeding programs in developing countries can generate sufficient gross margins to be self-sustaining. Our results show both breeding programs had substantial positive gross margins irrespective of the selection criteria. However, to maximize the profitability of the program, we further compared the economic effects of PT and GS selection criteria. Our results indicate that GS schemes will outperform equivalent PT schemes in gross margins. This outcome follows from the advantages accrued from GS selection criteria discussed earlier (i.e., shorter generation intervals and lower operational costs). The overall effect of these advantages was higher genetic gain in the commercial population that translated to higher gross margins for GS schemes (Schaeffer, 2006; König et al., 2009).

Besides the effect on genetic gains, generation intervals also influence the extent of discounting. Prolonged L in PT schemes not only delays expressions but also leads to a higher reduction of the monetary value of the expressed superiorities because of the effect of time on the value of money (Brascamp, 1978). Therefore, in addition to higher cumulative genetic gain in the commercial population, breeding programs selecting parents on genomic estimated breeding values stand to benefit from a smaller effect of discounting on the monetary value of revenues.

We fixed the discount rate at 2 levels (i.e., 4 and $7 \%$ ). Animal breeding investment appraisals should be considered as public ventures and as such should take a social discount rate (Smith, 1978). Social discount rates range between 2 and 5\% (Bird and Mitchell, 1980). However, it may be argued that breeding programs for developing dairy industries targeted for smallholder production systems face a higher risk of not obtaining any returns compared with those for developed industries (Marshall et al., 2011). To account for such risk we used an upper discount rate of $7 \%$ (Brascamp, 1978). Discount rates used in studies focused on tropical dairy systems in the literature ranged between 3 and 10\% (Mpofu et al., 1993; Kahi et al., 2004; Okeno et al., 2010a). Our results showed that even with higher discount rates, small-sized nucleus dairy cattle schemes in developing countries are profitable.

\section{Practical Considerations}

To optimize efficiency of the developing dairy cattle industries in tropical environments, it is imperative to match genotypes to the production circumstances (Kosgey et al., 2006; Rege et al., 2011). This goal can be achieved by implementation of locally run breeding programs selecting for breeding objectives that reflect the production realities of tropical production systems.

For breeding programs in developing countries, having a holistic view of all factors that may influence success is important (Kosgey et al., 2006). For such programs to be successful, careful planning is needed 
(Marshall et al., 2011). Conventionally, dairy cattle breeding has been based on progeny-testing programs. However, the biggest hindrances to the implementation of conventional dairy cattle breeding programs in the tropics are poor infrastructure for PT with unreliable commitment of participating farmers and inconsistent pedigree and performance recording by producers (Wasike et al., 2011). For developing industries, the few farms participating in recording are usually the best performing farms with the best cows. To implement a PT-based breeding program would therefore require such farms to be willing to use young untested bulls. Such willingness may be lacking. Moreover, high rates in dropout and entrance of new producers increases volatility in the breeding program. For PT schemes, this situation poses a challenge because a specific family relationship needs to be maintained between the CRC and bull selection candidates.

However, a GS scheme can be established by using the available recorded cows to form a reference population. Cows with phenotypes can be genotyped, and this information can be used to estimate SNP effects, which in turn can be used for evaluation. This circumstance presents 2 major advantages for the success of a GS for developing dairy industries. First, direct relationship between the selection candidate and the recorded cows is eliminated. Accuracies of genomic breeding values are higher when the reference population is closely related to the selection candidates (Bastiaansen et al., 2012), which is the case in our present study. In addition, for the high dropout rates DNA can be used to reconstruct the pedigree. This reconstruction minimizes the adverse effects of high volatility of producer participation in recording on success of evaluation of bulls, which in turn increases the chances for success of GS schemes. Second, with GS, evaluation of bull selection candidates is not dependent on test daughter performances. Therefore, pedigree and performance information from top farms can be used to evaluate young bulls without requiring these farms to use untested bulls on their cows.

In this study our goal was to investigate the economic performance of PT and GS for a small-sized breeding program. Therefore, we intentionally considered a small nucleus size as a benchmark, the reasoning being that profitability is bound to be higher with larger breeding programs (Schaeffer, 2006; König et al., 2009). Our results show that GS is superior to PT for developing dairy cattle industries. However, besides economic performance, the minimum size of a breeding program will further depend on the rate of inbreeding. Although inbreeding was not considered for simplicity, consideration of the effect of the alternative selection strategies on the rate of inbreeding is important. Irrespective of the size of a breeding program, GS will have less build- up of inbreeding over time because the strategy can explain some of the variation due to Mendelian sampling hence minimize co-selection of siblings (Daetwyler et al., 2007). In addition, accumulation of inbreeding can be minimized by increasing the nucleus size and minimizing co-ancestry in the parents (Meuwissen, 1997; Sonesson and Meuwissen, 2001). Increasing the nucleus size with GS is relatively easier than with PT because an increase in nucleus size for PT must be accompanied by an increase in the size of the CRC population.

\section{CONCLUSIONS}

Small-sized nucleus dairy breeding programs in developing countries can generate sufficient revenues to secure their sustainability. In addition, GS schemes will outperform PT schemes on genetic gains and economic performance. Higher performance of GS is explained by the short generation intervals, lower operation costs, and less discounting of revenues. In addition, breeding programs could benefit from cost-cutting measures such as semen storage and early culling of bulls. Ultimately, implementation of a breeding program and choice of selection strategy will be determined by the ability to generate profit. Genetic selection schemes will not only yield higher gross margins compared with PT schemes but are also less demanding in terms of infrastructure and performance recording. We therefore conclude that small-sized GS nucleus dairy cattle schemes are economically feasible for developing dairy cattle industries.

\section{ACKNOWLEDGMENTS}

The authors are grateful to The Netherlands Organization for International Cooperation in Higher Education (NUFFIC, The Hague, the Netherlands) for financing this study. We also gratefully acknowledge the input from the stakeholders in the workshop.

\section{REFERENCES}

Bastiaansen, J. W. M., A. Coster, M. P. L. Calus, J. A. M. van Arendonk, and H. Bovenhuis. 2012. Long-term response to genomic selection: Effects of estimation method and reference population structure for different genetic architectures. Genet. Sel. Evol. 44:3.

Bird, P. J. W. N., and G. Mitchell. 1980. The choice of discount rates in animal breeding investment appraisal. Anim. Breed. Abstr. 48:499-505.

Brascamp, E. W. 1978. Methods on Economic Optimization of Animal Breeding Plans. Report B-134. Research Institute for Animal Husbandry, Zeist, the Netherlands.

Brascamp, E. W., J. A. M. van Arendonk, and A. F. Groen. 1993. Economic appraisal of the utilization of genetic markers in dairy cattle breeding. J. Dairy Sci. 76:1204-1213.

Bulmer, M. G. 1971. The effect of selection on genetic variability. Am. Nat. 105:201-211.

CBK. 2016. Central Bank Rates. Accessed July 26, 2016. https:// www.centralbank.go.ke/rates/central-bank-rate/. 
Daetwyler, H. D., B. Villanueva, P. Bijma, and J. A. Woolliams. 2007. Inbreeding in genome-wide selection. J. Anim. Breed. Genet. 124:369-376

Dekkers, J. C. M. 2007. Prediction of response to marker-assisted and genomic selection using selection index theory. J. Anim. Breed. Genet. 124:331-341.

Dekkers, J. C. M., and G. E. Shook. 1990. Genetic and economic evaluation of nucleus breeding schemes for commercial artificial insemination firms. J. Dairy Sci. 73:1920-1937.

Ducrocq, V., and R. L. Quaas. 1988. Prediction of genetic response to trunction selection across generations. J. Dairy Sci. 71:2543-2553.

Gizaw, S., T. Getachew, S. Goshme, A. Valle-Zarate, J. A. M. van Arendonk, S. Kemp, A. O. Mwai, and T. Dessie. 2014. Efficiency of selection for body weight in a cooperative village breeding program of Menz sheep under smallholder farming system. Animal $8: 1249-1254$

Goddard, M. E., and B. J. Hayes. 2002. Optimisation of response using molecular data. Page 3 in Proc. 7th World Congr. Appl. Livest. Prod. Montpellier, France, August 19-23, 2002.

Goddard, M. E., and B. J. Hayes. 2007. Genomic selection. J. Anim. Breed. Genet. 124:323-330.

Guichoux, E., L. Lagache, S. Wagner, P. Chaumeil, P. Leger, O. Lepais, C. Lepoittevin, T. Malausa, E. Revardel, F. Salin, and R. J. Petit. 2011. Current trends in microsatellite genotyping. Mol. Ecol. Resour. 11:591-611.

Hazel, L. N. 1943. The genetic basis for constructing selection indexes. Genetics 28:476-490.

Hinks, C. J. M. 1974. The planning and organization of progeny testing with particular reference to numerically small populations and breeds of dairy cattle. Z. Tierz. Zuchtungsbio. 91:169-175.

Kahi, A. K., and G. Nitter. 2004. Developing breeding schemes for pasture based dairy production systems in Kenya: I. Derivation of economic values using profit functions. Livest. Prod. Sci. 88:161-177.

Kahi, A. K., G. Nitter, and C. F. Gall. 2004. Developing breeding schemes for pasture based dairy production systems in Kenya: II. Evaluation of alternative objectives and schemes using a two-tier open nucleus and young bull system. Livest. Prod. Sci. 88:179-192.

Kariuki, C. M., H. Komen, A. K. Kahi, and J. A. M. van Arendonk. 2014. Optimizing the design of small-sized nucleus breeding programs for dairy cattle with minimal performance recording. J. Dairy Sci. 97:7963-7974.

König, S., H. Simianer, and A. Willam. 2009. Economic evaluation of genomic breeding programs. J. Dairy Sci. 92:382-391.

Kosgey, I. S., R. L. Baker, H. M. J. Udo, and J. A. M. van Arendonk. 2006. Successes and failures of small ruminant breeding programmes in the tropics: A review. Small Rumin. Res. 61:13-28.

Marshall, K., C. Quiros-Campos, J. H. J. van der Werf, and B. Kinghorn. 2011. Marker-based selection within smallholder production systems in developing countries. Livest. Sci. 136:45-54.

Mburu, L. M., J. W. Wakhungu, and W. G. Kang'ethe. 2007. Characterization of smallholder dairy production systems for livestock improvement in Kenya highlands. Livest. Res. Rural Dev. 19:110.

Meuwissen, T. H. E. 1991. Reduction of selection differentials in finite populations with a nested full-half sib family structure. Biometrics 47:195-203.

Meuwissen, T. H. E. 1997. Maximizing the response of selection with a predefined rate of inbreeding. J. Anim. Sci. 75:934-940.
Meuwissen, T. H. E., B. J. Hayes, and M. E. Goddard. 2001. Prediction of total genetic value using genome-wide dense marker maps. Genetics 157:1819-1829.

Mpofu, N., C. Smith, W. van Vuuren, and E. B. Burnside. 1993 Breeding strategies for genetic improvement of dairy cattle in Zimbabwe: 2. Economic evaluation. J. Dairy Sci. 76:1173-1181.

Muasya, T. K., K. J. Peters, and A. K. Kahi. 2013. Breeding structure and genetic variability of the Holstein Friesian dairy cattle population in Kenya. Anim. Genet. Resourc. 52:127-137.

Mubiru, S. L., J. S. Tenywa, N. Halberg, D. Romney, W. Baltenweck, and S. Staal. 2007. Categorization of dairy production systems: A strategy for targeting meaningful development of the systems in Uganda. Livest. Res. Rural Dev. 19:100.

Nicholas, F. W., and C. Smith. 1983. Increased rates of genetic change in dairy cattle by embryo transfer and splitting. Anim. Prod. $36: 341-353$

Ojango, J. M. K., and G. E. Pollot. 2002. The relationship between Holstein bull breeding values for milk yield derived in both the UK and Kenya. Livest. Prod. Sci. 74:1-12.

Okeno, T. O., I. S. Kosgey, and A. K. Kahi. 2010a. Economic evaluation of breeding strategies for improvement of dairy cattle in Kenya. Trop. Anim. Health Prod. 42:1081-1086.

Okeno, T. O., I. S. Kosgey, and A. K. Kahi. 2010b. Genetic evaluation of breeding strategies for improvement of dairy cattle in Kenya. Trop. Anim. Health Prod. 42:1073-1079.

Rege, J. E. O., K. Marshall, A. Notenbaert, J. M. K. Ojango, and A. M. Okeyo. 2011. Pro-poor animal improvement and breedingWhat can science do? Livest. Sci. 136:15-28.

Rutten, M. J. M., P. Bijma, J. A. Woolliams, and J. A. M. van Arendonk. 2002. SelAction: Software to predict selection response and rate of inbreeding in livestock breeding programs. J. Hered. 93:456-458.

Schaeffer, L. R. 2006. Strategy for applying genome-wide selection in dairy cattle. J. Anim. Breed. Genet. 123:218-223.

Shendure, J., and E. L. Aiden. 2012. The expanding scope of DNA sequencing. Nat. Biotechnol. 30:1084-1094.

Skjervold, H., and H. J. Langholz. 1964. Factors affecting the optimum structure of A.I. breeding in dairy cattle. Z. Tierz. Zuchtungsbio. 80:25-40.

Smith, C. 1978. The effect of inflation and form of investment on the estimated value of genetic improvement in farm livestock. Anim. Prod. 26:101-110.

Sonesson, A. K., and T. H. E. Meuwissen. 2001. Minimization of rate of inbreeding for small populations with overlapping generations. Genet. Res. 77:285-292.

Vargas, B., and J. A. M. van Arendonk. 2004. Genetic comparison of breeding schemes based on semen importation and local breeding schemes: Framework and application to Costa Rica. J. Dairy Sci. $87: 1496-1505$

Villanueva, B., N. R. Wray, and R. Thompson. 1993. Prediction of asymptotic rates of response from selection on multiple traits using univariate and multivariate best linear unbiased predictors. Anim. Prod. 57:1-13.

Wasike, C. B., T. M. Magothe, A. K. Kahi, and K. J. Peters. 2011. Factors that influence the efficiency of beef and dairy cattle recording system in Kenya: A SWOT-AHP analysis. Trop. Anim. Health Prod. 43:141-152. 